\title{
SOLAR POWERED STIRLING ENGINE DRIVEN WATER PUMP
}

\author{
Anish Saini ${ }^{1}$, Shivam Kohli ${ }^{2}$, AjeshJ.Pillai ${ }^{3}$ \\ ${ }^{1,2,3}$ Student, Department of Mechatronics, Manipal Institute of Technology, Karnataka, India, \\ anish.saini20@gmail.com, shivamkohli509@ymail.com,ajeshmit@gmail.com
}

\begin{abstract}
Depletion of non-renewable resources has been a major problem that we face in today's world, thus taking this into consideration, in this paper we deal with the powering of water pump using solar energy, for this purpose we use the principle of stirling cycle to achieve the desired result. Parabolic mirror is used to concentrate the solar beams onto the area where enough energy is produced to drive the stirling engine which works on the basic principal of the conversion of the heat energy to mechanical work depending on the heat difference being provided. A country like India, where energy crisis is a frequently observed problem, our system could be of great use especially in the areas where water deficiency is high, where shortage of electricity is a known fact. Our system uses the only abundant renewable energy that is the sun light for drawing out water from underground water beds which can be used to generate electric power, this method can act as an important tool.
\end{abstract}

Keywords: Stirling engine, temperature difference, load, solar energy, water pump.

\section{INTRODUCTION}

Mankind has been dwelling on this planet for a very long time and the natural resources available are getting depleted at a faster rate than before, we believe it's time for us to look up to the sky for energy. With the continuous depletion of nonrenewable resources which has formed the basic power source of energy for mankind for hundreds of years and the continuous unlimited availability of renewable resources such as solar, wind etc. all the attention is being focused on extracting energy from the renewable resources and simultaneously reduce the load over the depleting ones. Apart from many benefits like nonpolluting, abundance in their reserves, these renewable resources provides us with a very lucrative energy resource which if properly utilized can power the whole energy needs of the world. In this paper we discuss a basic technique to develop mechanical energy using conventional renewable resource that is solar energy. The energy from the sun is very important to us; apart from the fact that it gives us warmth, causes the water cycle, currents in the oceans and generates photosynthesis in plants, it can also be confined and converted to energy in a numerous number of ways. Solar energy is the most abundant and easily available renewable resource, and has been harnessed by humans since ancient times. In one year, the Sun delivers more than 10,000 times the energy that humans currently use and almost twice the amount of energy that will ever be obtained from all of the planet's non-renewable resources. For instance, the solar power when sun hits the atmosphere is $10^{17}$ Watts, whereas the solar power on the earth's surface is $10^{16}$ Watts. The total worldwide power demand of all needs of civilization is $10^{13}$ watts [4]. If we can use even $5 \%$ of this energy, it will be 50 times of what the world requires. Moreover, all water power other than tidal power also represents the utilization of solar energy. For instance, heat from the sun causes the evaporation of surface waters, the vapors that rises is condensed in the upper atmosphere, and falls as rain. So our concept basically uses solar energy to drive an engine which basically can be utilized for doing mechanical works such as pumping water from the underground water tables. Figure1. Represents the basic difference between the energy given by renewable energy and current requirement of energy by the whole world.

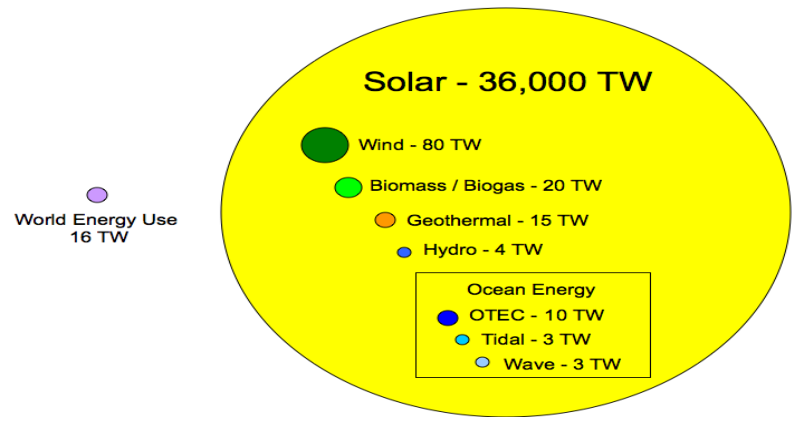

Fig -1: Renewable Energy Vs Current World Energy use (yearly).

\section{STIRLING ENGINE}

A Stirling engine is a heat engine operating by cyclic compression and expansion of air or other gas, the working fluid, at different temperature levels such that there is a net conversion of heat energy to mechanical work. The main difference between a Stirling engine and other engines is that it's an external combustion engine.No combustion takes place 
inside the cylinders of the engine. The gases used inside a Stirling engine never leave the engine i.e. it's completely sealed. There are no exhaust valves that vent high-pressure gases, as in a gasoline or diesel engine, and there are no explosions taking place. Because of this, Stirling engines are very quiet with their operation.

\subsection{Working Principle}

The fixed amount of gases is enclosed in totally sealed medium and they can never escape out of it. Pressure of gas inside the cylinder changes due to various events like heating from outside sources etc. which causes this engine to work [3] [4]. There are some properties of gasses that are important for the normal operation of Stirling engines:

- If we have a fixed amount of gas in a fixed volume of space and we raise the temperature of that gas, the pressure will also increase.

- If we have a fixed amount of gas and we compress it (decrease the volume of its space), the temperature of that gas will increase.

The basic working of each stroke of Stirling engine is explained below:

\section{RED END $=$ HOT END \\ BLUE END $=$ COLD END}

\subsection{Expansion Stroke}

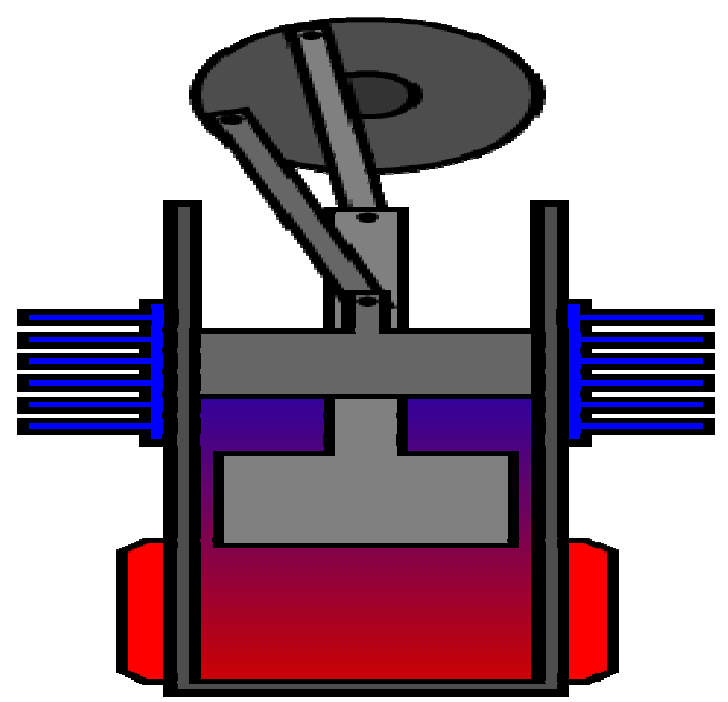

Fig -2: Expansion stroke of Stirling cycle.

Gas at hot end expands to drive power piston. Power piston (dark grey) has compressed the gas, the displacer piston (light grey) has moved so that most of the gas is adjacent to the hot heat exchanger.

\subsection{Power Stroke}

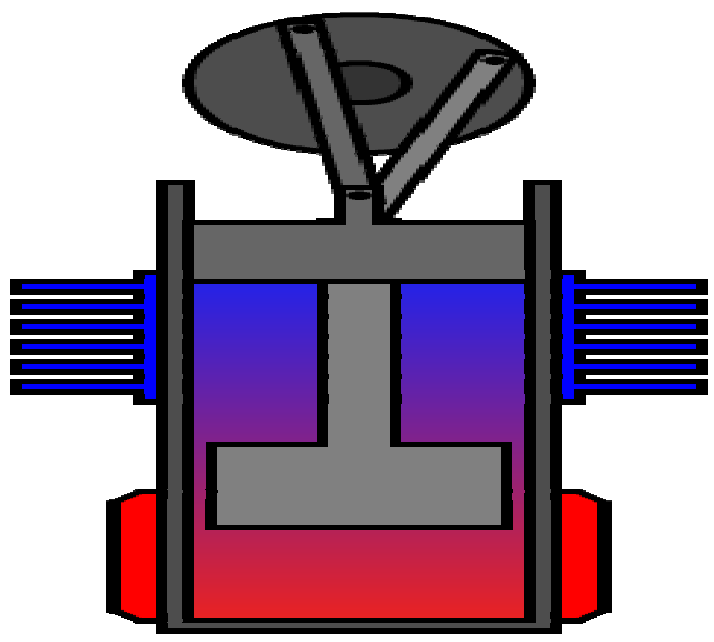

Fig -3: Power stroke of Stirling cycle.

Gas is moved around the displacer to the cold end. The pressure of heated gas increases and pushes the power piston to the farthest limit of the power stroke.

\subsection{Contraction stroke}

Gas has moved to the cold end. Gas cools and contracts, allowing the piston inward. The displacer piston now moves, allowing the gas to the cold end.

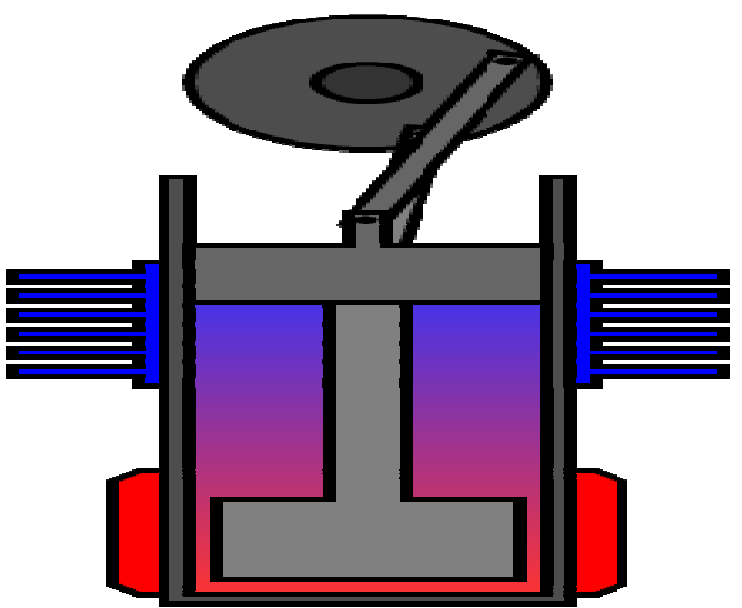

Fig -4: Contraction stroke of Stirling cycle.

\subsection{Transfer Stroke}

Air is fully cooled at the cold end of the cylinder.The cooled gas is now compressed by the flywheel momentum. Flywheel momentum transfers gas to hot end. This process takes less energy because its pressure drops when it's cooled. 


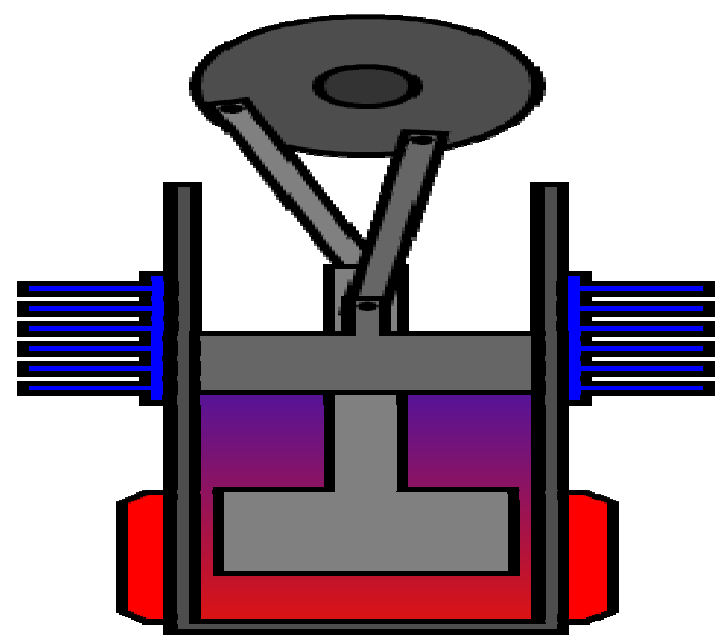

Fig -5: Transfer stroke of Stirling cycle end.

\section{SOLAR BEAM CONCENTRATOR}

Concentrated solar power systems use mirrors or lenses to concentrate a large area of sunlight, or solar thermal energy, onto a smallarea. Electrical power is Electrical power is high as $4000 \mathrm{C}$. The thermal efficiency ranges from $60 \%-80 \%$ [2][8]. The solar beam concentrator is designed to take advantage of the parabolic curve performance of a reflector which is most efficient means of collecting solar energy onto a focal point where an absorber is located[8].

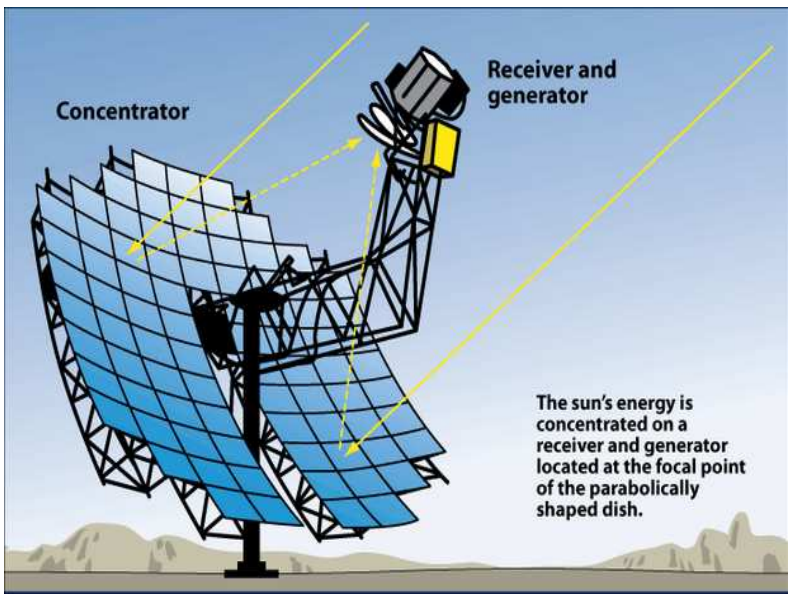

Fig -6: Solar Beam Concentrator.

\section{CENTRIFUGAL PUMP}

A centrifugal pump is a mechanical device that applies mechanical energy given by a motor to drive the fluid. The reverse function of the centrifugal pump is a water turbine converting potential energy of water pressure into mechanical rotational energy.

\subsection{Working of Centrifugal Pump}

Centrifugal pumps are used to transport fluids by the conversion of rotational kinetic energy to the hydrodynamic energy of the fluid flow. The rotational energy typically comes from an engine or electric motor. The fluid enters the pump impeller along or near to the rotating axis and is accelerated by the impeller, flowing radially outward into a diffuser or volute chamber (casing), from where it exits [6].

The power required to drive a pump, is defined simply using SI units by [9] :

$$
P_{i}=\frac{\rho g H Q}{\eta}
$$

Where:

Piis the input power required $(\mathrm{W})$

$\rho$ is the fluid density $(\mathrm{kg} / \mathrm{m} 3)$

$\mathrm{g}$ is the standard acceleration of gravity $(9.80665 \mathrm{~m} / \mathrm{s} 2)$

$\mathrm{H}$ is the energy Head added to the flow (m)

$\mathrm{Q}$ is the flow rate $(\mathrm{m} 3 / \mathrm{s})$

$\eta$ is the efficiency of the pump plant as a decimal
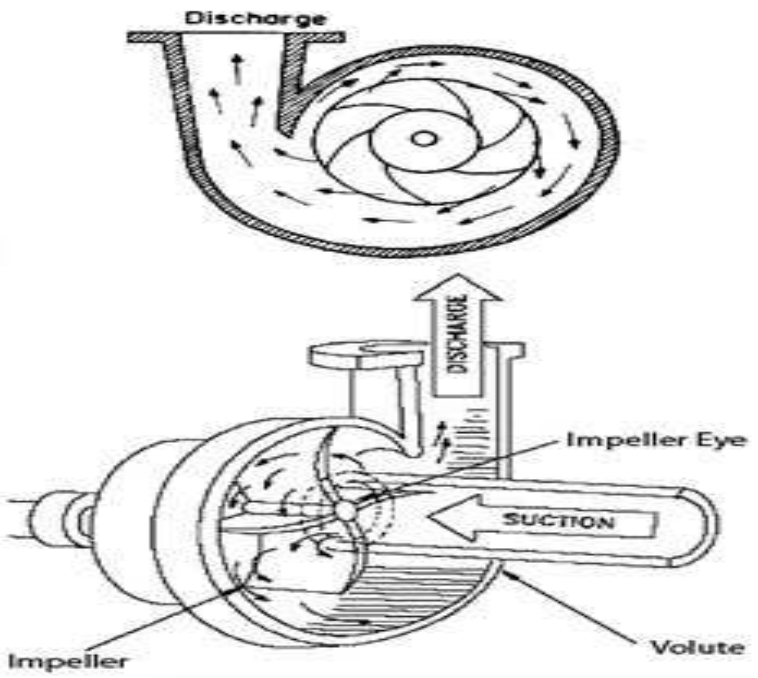

Fig -7: Centrifugal Pump.

\section{FLYWHEEL ENERGY STORAGES (FES)}

In flywheel energy storage rotational energy is stored in an accelerated rotor, a massive rotating cylinder. The main components of a flywheel are the rotating body/cylinder comprised of a rim attached to a shaft) in a compartment, the bearings and the transmission device (motor/generator mounted onto the stator). The energy is maintained in the flywheel by keeping the rotating body at a constant speed[5]. 
An increase in the speed results in a higher amount of energy stored.

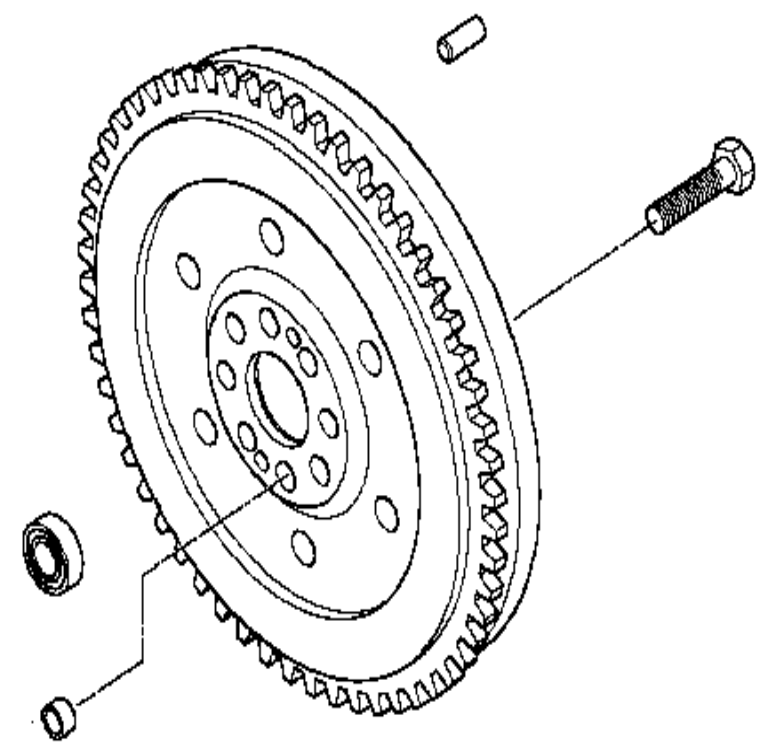

Fig -8: Flywheel

\section{WORKING OF THE SYSTEM}

Solar energy is the main source of heat in this mechanism. A completely sealed glass covering is provided near the hot end so that the heat entrapped inside the sealed medium won't be able to escape out into the atmosphere. This will lead to a high temperature rise inside the medium.

A parabolic mirror (dish type solar concentrator) converge the entire solar rays that falls on its surface onto its focal point. Solar energy drives the entire system. The expected output from the stirling engine is approximately $3 \mathrm{~kW}$ and it can drive the centrifugal pump at a rpm of about 500-1,500rpm[1] [7]. A gearmechanism can be used to achieve high rpm or high torque.

Solar energy is directed to hot end of Stirling engine by the dish type solar concentrator.Initial momentum is given to the flywheel of stirling engine which can be related to the starting of a vehicle using the key.Once the ambient temperature (5000c) at the focus point is achieved, the displacer piston moves forward thereby forcing the power piston to move.Therefore the power stroke of Stirling engine is achieved.

The force achieved by the power piston is transferred to the flywheel; it acts as an energy reservoir. The Flywheel transfers the rotary motion to the vane of centrifugal pump which is connected to the same shaft. Due to rotary motion of centrifugal pump, vacuum is created at the inlet port which thereby drives the fluid from the sump to the outlet pipe.During the transfer stroke the forward movement (movement of piston from cold end to hot end) is assisted by two forces:

- The momentum of the flywheel.

- Pull created inside the cylinder due to the reduction of pressure of gases sealed inside the cylinder.

Hence the cycle is repeated and we achieve continuous output from the stirling engine which thereby drives the centrifugal pump continuously.

Table -1: Design Parameters of the System.

\begin{tabular}{|l|l|}
\hline Engine Type & 2 Piston \\
\hline Main Energy Source & Solar Energy \\
\hline Working Fluid & Helium \\
\hline Mean Pressure & $3-6 \mathrm{MPa}$ \\
\hline Max. Expansion Space Temp. & $975 \stackrel{ \pm}{-} 50 \mathrm{~K}$ \\
\hline Max. Shaft Power & $3 \mathrm{KW}$ \\
\hline Engine Speed & $500-1500 \mathrm{rpm}$ \\
\hline Output Mechanism Type & 60 deg. V Crank \\
\hline Flywheel Inertia & $0.9 \mathrm{Kg} \mathrm{m}$ \\
\hline
\end{tabular}

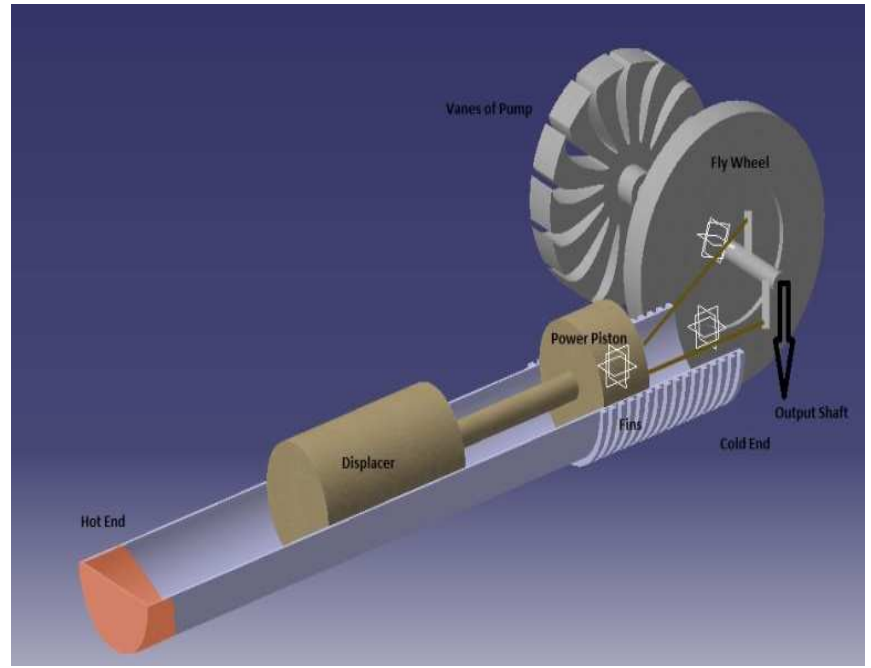

Fig -9 Final Assembly of Sterling Engine and Centrifugal Pump 


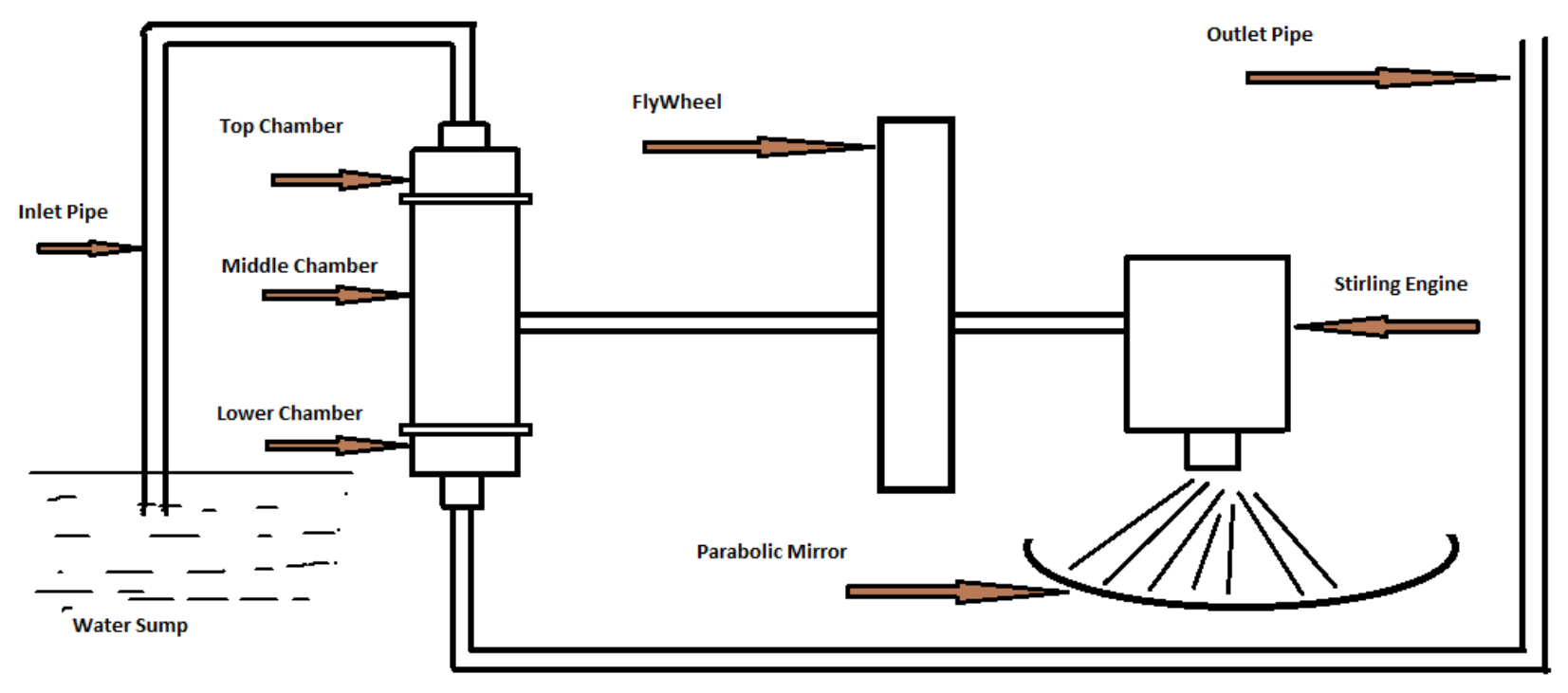

Fig -10: Block Diagram of the System.

\section{CONCLUSIONS}

Excess dependence on nonrenewable resources over the past few centuries has revealed their hiddenweaknesses. In the past few decades, intensifying environmental problems, increasing worry over secure supply chains and economic instability due to unpredictable energy prices have routinely plagued industries and developing nations as they strive to meet evergrowing energy demands. Although there are still technological hurdles to clear before renewable energy can be efficiently exploited, the economic and environmental benefits of renewables suggest that this is a sound area of investment.This is the most efficient and economical way of driving the centrifugal pump as the solar energy is used for this purpose. The normal way of driving centrifugal pump is using electricity which consumes a lot of kilowatts of power and hence leads to wastage of solar energy which being renewable and replenish-able source, therefore it is sustainable and will never run out. The best part of this system is its low maintenance cost, zero operation cost and no impact on the environment.

\section{REFERENCES}

[1]. Noboru Kagawa Associate Professor, AIAA-20002814EXPERIMENTAL STUDY OF A 3-KW STIRLING ENGINE

[2]. R.Aishwarya,K.DhivyaBharathi2011 International Conference on Recent Advancements in Electrical, Electronics and Control EngineeringSolar Powered Stirling Engine for Self-Generating Electricity
[3]. P. T. Gaynor*, R. Y. Webb*, and C. C. Lloyd Low Enthalpy Heat Stirling Engine Based Electric Power Generation: A Research Design978-1-4244-2544-0/08/\$20.00 C2009 IEEE

[4]. Mike He, NicBeutler, Denise Loeder, and Seth SandersTesting of $2.5 \mathrm{~kW}$ Low Temperature Stirling Engine for Distributed Solar Thermal Generation978-1-4673-18358/12/\$31.00 @2012 IEEE

[5]. S.D. Allan (2005). "World's Largest Solar Installation to use Stirling Engine Technology". Pure Energy Systems News. [6]. Kagawa, N. et al., Development of a 3 kW Stirling Engine for a Residential Heat Pump System. Proc4* ICSE. 1988. Tokyo: JSME, pp.1-6.

[7]. Kagawa, N. et al., Performance Analysis and Improvement of a $3 \mathrm{~kW}$ Stirling Engine. Proc. 21St IECEC. 1986. San Diego: ACS No. 869109.

[8]. Howard, D.; Harley, R.G.; "Modeling of dish-Stirling solar thermal power generation," Power and Energy Society General Meeting, 2010 IEEE , vol., no., pp.1-7, 25-29 July 2010.

[9]. BahaAbulnaga (2004). Pumping Oilsand Froth.21st International Pump Users Symposium, Baltimore, Maryland. Published by Texas A\&M University, Texas, USA. 


\section{BIOGRAPHIES}

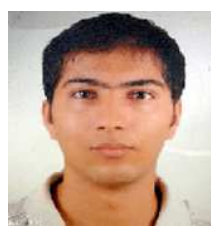

Shivam Kohli is a final year BE student at Manipal Institute of Technology in the Department of Mechatronics. His current research interests include biomedical sensors, robotics, automation, engines, Hydraulics and Automation, and autotronics

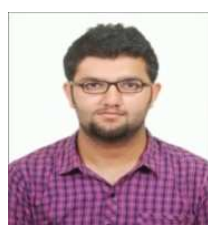

Anish Saini is a final year BE student at Manipal Institute of Technology in the Department of Mechatronics. His current research interests include biomedical sensors, robotics, automation, engines, mechanical design, and autotronics.

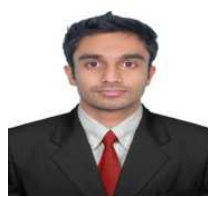

Ajesh J. Pillai is a final year B.E. student at Manipal Institute of technology in the Department of Mechatronics. His current research interest include automation, autotronics and manufacturing techniques 